\title{
Association of matrix metalloproteinase-9 C1562T polymorphism and coronary artery disease: a meta-analysis
}

\author{
Xiao WANG ${ }^{1}$, Lei-zhi SHI ${ }^{\dagger 1,2}$

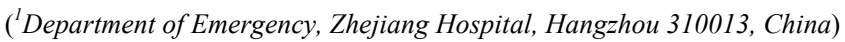 \\ ('Department of Thoracic Minimally Invasive Surgery, Linyi People's Hospital, Linyi 276000, China) \\ †E-mail: shileizhi@163.com \\ Received Mar. 26, 2013; Revision accepted Aug. 12, 2013; Crosschecked Feb. 28, 2014
}

\begin{abstract}
Objective: Many investigations have studied the associations between matrix metalloproteinase-9 (MMP-9) C1562T polymorphisms and coronary artery disease (CAD). However, the conclusions of these studies were inconsistent. Therefore, this study was aimed at clarifying the association between MMP-9 C1562T polymorphisms and CAD in a large-scale meta-analysis. Methods: The PubMed and Embase databases were retrieved to collect all publications on the association between MMP-9 C1562T polymorphisms and CAD. Then the odd ratios (ORs) and 95\% confidence intervals $(95 \% \mathrm{Cls})$ for $\mathrm{C} 1562 \mathrm{~T}$ TT+TC versus CC genotype between CAD and the control groups were evaluated. Subgroup analysis was also performed according to different races. The meta-analysis was performed by Stata 10.0. Results: Sixteen case-control studies were included in our meta-analysis, involving 11032 CAD patients and 4628 non-CAD controls. Compared with $\mathrm{C}$ allele carriers, East Asian T allele carriers TT+TC had a significantly higher risk of $\mathrm{CAD}(\mathrm{OR}=1.43 ; 95 \% \mathrm{Cl}$ : 1.03-1.99; $P=0.031)$; however, there were no significant associations in Western populations $(\mathrm{OR}=1.06 ; 95 \% \mathrm{Cl}$ : 0.96-1.18; $P=0.240)$ or West Asians $(\mathrm{OR}=1.13 ; 95 \% \mathrm{Cl}$ : $0.75-1.70 ; P=0.565)$. When further analyzing the association between $\mathrm{C} 1562 \mathrm{~T}$ polymorphisms and myocardial infarction (MI, the most serious type of $\mathrm{CAD}$ ), the risk of TT+TC genotype versus $\mathrm{CC}$ genotype for MI was significantly higher for the overall $(\mathrm{OR}=1.21 ; 95 \% \mathrm{Cl}: 1.04-1.40 ; P=0.012)$ and for East Asians (OR=1.58; 95\% Cl: $1.26-1.97 ; P=0.000)$ but not in Western populations (OR=1.12; 95\% Cl: 0.99-1.26; $P=0.078)$. Conclusions: Our meta-analysis suggested an obvious ethnic difference in the association between MMP-9 C1562T polymorphisms and CAD. MMP-9 C1562T polymorphism was significantly related to CAD in East Asians. However, no significant associations were observed in either West Asians or Western populations.
\end{abstract}

Key words: Coronary artery disease, Matrix metalloproteinase-9, Polymorphism, Meta-analysis doi:10.1631/jzus.B1300088 Document code: A $\quad$ CLC number: R541.4

\section{Introduction}

Coronary artery disease (CAD) is a multifactorial, complicated disease and is the leading cause of mortality in most low- and middle-income countries (Lopez et al., 2006). Its exact underlying mechanisms are still not fully understood. However, interaction between gene and environment may be particularly relevant (Marenberg et al., 1994). In recent years, many studies have focused on the association be-

\footnotetext{
Corresponding author

(C) Zhejiang University and Springer-Verlag Berlin Heidelberg 2014
}

tween polymorphic variants in candidate genes and CAD. Among them, matrix metalloproteinase-9 (MMP-9) is one of the potentially relevant candidate genes.

MMP-9, also known as gelatinase B or 92-kDa type IV collagenase, is one member of the MMP family, which forms a large family of zinc-dependent enzymes that can degrade the extracellular matrix and contribute to both normal and pathological tissue remodeling (Newby, 2005). Epidemiological study has indicated that the higher plasma concentration of MMP-9 may be a predictor of cardiovascular disease risk (Blankenberg et al., 2003). The MMP-9 gene has 
three major polymorphisms in the promoter, coding and untranslated regions (Zhang et al., 1999b). Of these, the $\mathrm{C} 1562 \mathrm{~T}$ (rs3918242) polymorphism $(\mathrm{C} \rightarrow \mathrm{T})$ in the promoter region is of special interest, for many studies have found a close association between C1562T polymorphism and CAD (Cho et al., 2002; Morgan et al., 2003; Koh et al., 2008; Zhi et al., 2010) However, some other studies (Haberbosch and Gardemann, 2005; Alp et al., 2009) did not found such a close relationship.

These studies drawing different conclusions make us puzzled, as one single study may fail to completely demonstrate the complex relationship. Therefore, we performed a meta-analysis to resolve this issue.

\section{Materials and methods}

\subsection{Study selection}

We searched the PubMed and Embase databases to collect all publications on the association between MMP-9 C1562T polymorphisms and CAD (last search update: Sept. 25, 2011). The language was limited to English only. The following key words were used: MMP-9 or "matrix metalloproteinase-9" or "gelatinase B" or "type IV collagenase"; polymorphism or SNPs or "polymorphism, single nucleotide" or genotype or mutation or variants; "coronary artery disease" or "coronary heart disease" or "ischemic heart disease" or "stable angina" or "unstable angina" or "myocardial infarction" or "acute coronary syndrome". Then the results were combined by the Boolean operator "AND". We further retrieved reference lists from included papers to avoid missing any relevant studies. The following criteria should be satisfactory for the included papers in our metaanalysis: (1) case-control study; (2) only CAD as the study outcome and the site should be C1562T; (3) the control group should not have any disease that is related to $\mathrm{CAD}$; (4) the distribution of genotypes in $\mathrm{CAD}$ and control groups should be obtained directly or according to calculation; and (5) the genotype distribution in the control group should meet the Hardy-Weinberg equilibrium.

\subsection{Data extraction}

Two authors independently extracted the following information from included publications: the first author's name, publication year, region of study origin, age of patients, number of men/women, and number of patients in different genotypes. If there were any disagreements, a consensus was agreed by discussion.

\subsection{Statistical analysis}

The meta-analysis was performed by Stata 10.0 software (Stata, College Station, Texas, USA). First, the overall odd ratios (ORs) and 95\% confidence intervals (CIs) for C1562T TT+TC versus CC genotype between CAD and the control groups were analyzed. Subgroup analysis was further conducted according to different races. A heterogeneity test was assessed by chi-square-based $Q$ test and $I^{2}$ test. A fixed-effect model was used to evaluate the OR and $95 \% \mathrm{CI}$ if no significant heterogeneity $(P>0.05$ and $\left.I^{2}<25 \%\right)$ existed. Otherwise, a random-effect model was selected. Publication bias was evaluated by Begg's funnel plot and Egger's test; a $P$ value $>0.05$ was considered as no potential publication bias.

\section{Results}

\subsection{Characteristics of the included studies}

The literature search identified 122 potentially relevant papers (after excluding 44 duplicate studies). Ninety-six articles were removed after preliminary screening. Twenty-six studies were left for further review and 10 additional papers were excluded (Fig. 1). Finally, 16 papers (Pollanen et al., 2001; Wang J. et al., 2001; Cho et al., 2002; Kim et al., 2002; Morgan et al., 2003; Haberbosch and Gardemann, 2005; Nuzzo et al., 2006; Horne et al., 2007; Nanni et al., 2007; Koh et al., 2008; Alp et al., 2009; Fallah et al., 2010; Ghaderian et al., 2010; Zhi et al., 2010; Opstad et al., 2012; Wang L. et al., 2012) were included in our meta-analysis involving $11032 \mathrm{CAD}$ patients and 4628 non-CAD controls. We divided the included studies into three sections according to ethnicities: Western populations, East Asians, and West Asians. The sample sizes in each subgroup were 12581, 2909, and 1170 , respectively. The TT+TC distribution was similar or even lower in CAD than in control groups in Western populations $(22.5 \%$ vs. $24.8 \%)$ or West Asians (41.2\% vs. 47.8\%). However, in East Asians, the TT+TC distribution was much higher in the CAD group than in control subjects $(24.4 \%$ vs. $18.9 \%)$. 
A summary of included 16 articles is presented in Table 1.

\subsection{Meta-analysis}

Fig. 2 shows the outcomes of the meta-analysis and heterogeneity test. We selected a random-effect model to evaluate the ORs and $95 \%$ CIs for $Q$ test and $I^{2}$ test showed a modest heterogeneity $(P=0.053$, $\left.I^{2}=39.5 \%\right)$. Compared to CC genotype, TT+TC genotype was significantly associated with $\mathrm{CAD}$ overall $(\mathrm{OR}=1.16 ; 95 \% \mathrm{CI}: 1.03-1.31 ; P=0.018)$ and for East Asians (OR=1.43; 95\% CI: $1.03-1.99 ; P=0.031$ ). However, no significant association was observed in Western populations $(\mathrm{OR}=1.06$; $95 \%$ CI: $0.96-1.18$; $P=0.240$ ) or West Asians (OR=1.13; 95\% CI: 0.75 $1.70 ; P=0.565)$. We further made an analysis of C1562T polymorphisms with myocardial infarction (MI, the most serious type of CAD) from included studies (Pollanen et al., 2001; Haberbosch and Gardemann, 2005; Nuzzo et al., 2006; Horne et al., 2007; Koh et al., 2008; Ghaderian et al., 2010; Zhi et al., 2010; Opstad et al., 2012; Wang L. et al., 2012). Fig. 3 shows the detailed result. The relative risks of

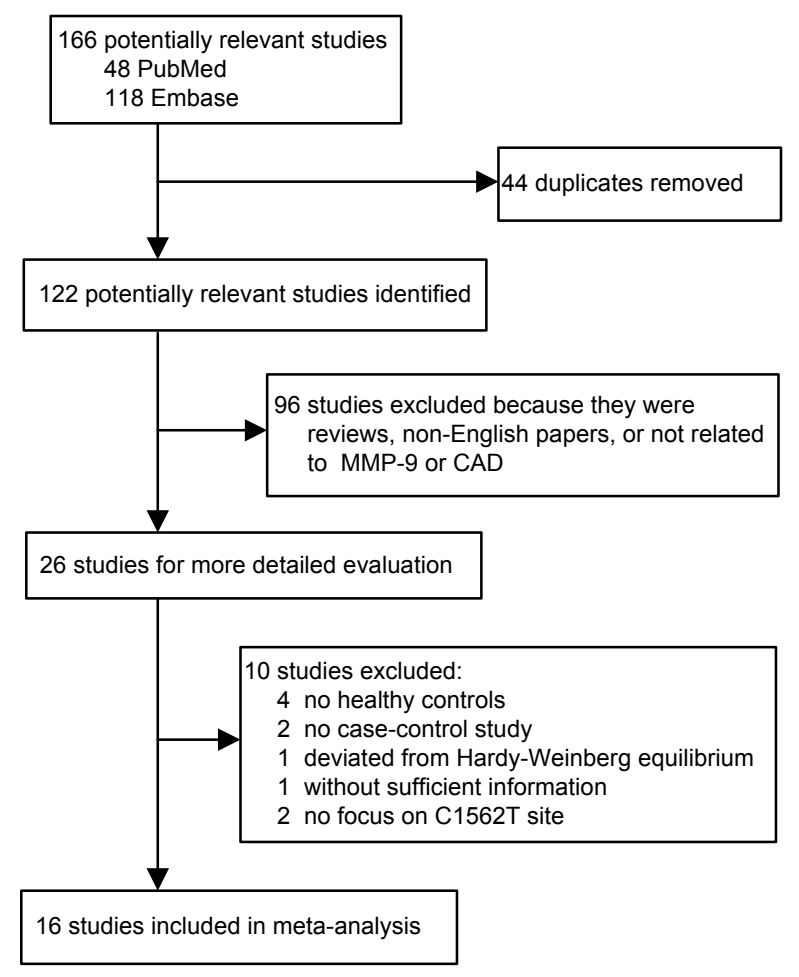

Fig. 1 Flow of included studies of this meta-analysis

Table 1 Characteristics of studies included in this meta-analysis

\begin{tabular}{|c|c|c|c|c|c|c|c|c|}
\hline \multirow[b]{2}{*}{ Study } & \multirow[b]{2}{*}{ Country } & \multirow[b]{2}{*}{ Ethnicity } & \multicolumn{3}{|c|}{ CAD } & \multicolumn{3}{|c|}{ Control } \\
\hline & & & $\begin{array}{c}\text { Gender } \\
\text { (male/female) }\end{array}$ & $\begin{array}{l}\text { Age }^{*} \\
\text { (year) }\end{array}$ & $(\mathrm{TT}+\mathrm{TC}) / \mathrm{CC}$ & $\begin{array}{c}\text { Gender } \\
\text { (male/female) }\end{array}$ & $\begin{array}{l}\text { Age }^{*} \\
\text { (year) }\end{array}$ & $(\mathrm{TT}+\mathrm{TC}) / \mathrm{CC}$ \\
\hline Pollanen et al., 2001 & Finland & Western & NA & NA & $31 / 78$ & NA & NA & $43 / 124$ \\
\hline Wang J. et al., 2001 & Australia & Western & NA & NA & $140 / 479$ & NA & NA & $41 / 128$ \\
\hline Morgan et al., 2003 & UK & Western & NA & NA & $219 / 779$ & NA & NA & $42 / 223$ \\
\hline $\begin{array}{l}\text { Haberbosch and } \\
\quad \text { Gardemann, } 2005\end{array}$ & Germany & Western & NA & NA & $502 / 1596$ & NA & $55.3 \pm 10.2$ & $121 / 414$ \\
\hline Nuzzo et al., 2006 & Italy & Western & $109 / 6$ & NA & $42 / 73$ & $100 / 53$ & NA & $37 / 86$ \\
\hline Horne et al., 2007 & USA & Western & $2748 / 912$ & NA & $968 / 3692$ & $550 / 572$ & $58.0 \pm 13.0$ & $292 / 830$ \\
\hline Nanni et al., 2007 & Italy & Western & NA & $47.8 \pm 6.2$ & $64 / 136$ & NA & $47.0 \pm 5.5$ & $66 / 135$ \\
\hline Opstad et al., 2012 & Norway & Western & $783 / 218$ & $62(36-81)$ & $240 / 756$ & $147 / 57$ & 55 & $50 / 154$ \\
\hline Kim et al., 2002 & Korea & East Asian & $89 / 42$ & $61.3 \pm 7.9$ & $32 / 99$ & $59 / 58$ & $59.3 \pm 8.5$ & $32 / 85$ \\
\hline Cho et al., 2002 & Korea & East Asian & $37 / 26$ & NA & $15 / 48$ & $36 / 31$ & $56.0 \pm 10.0$ & $4 / 63$ \\
\hline Koh et al., 2008 & Korea & East Asian & $125 / 81$ & $611 \pm 11.8$ & $55 / 151$ & $113 / 60$ & $58.3 \pm 11.8$ & $31 / 142$ \\
\hline Zhi et al., 2010 & China & East Asian & $543 / 219$ & $67.5 \pm 9.6$ & $177 / 585$ & $372 / 183$ & $69.9 \pm 11.8$ & $113 / 442$ \\
\hline Wang L. et al., 2012 & China & East Asian & $255 / 129$ & $55.6 \pm 10.9$ & $98 / 286$ & $291 / 160$ & $54.1 \pm 10.3$ & $78 / 373$ \\
\hline Alp et al., 2009 & Turkey & West Asian & $88 / 58$ & $59.3 \pm 9.1$ & $47 / 99$ & $59 / 63$ & $57.3 \pm 9.7$ & $32 / 90$ \\
\hline Ghaderian et al., 2010 & Iran & West Asian & $324 / 74$ & NA & $104 / 296$ & $111 / 89$ & NA & $59 / 141$ \\
\hline Fallah et al., 2010 & Iran & West Asian & $75 / 70$ & $58.4 \pm 9.1$ & $134 / 11$ & $80 / 77$ & $55.4 \pm 9.4$ & $138 / 19$ \\
\hline
\end{tabular}

" Data are expressed as mean \pm standard deviation or mean (range). NA: not applicable 


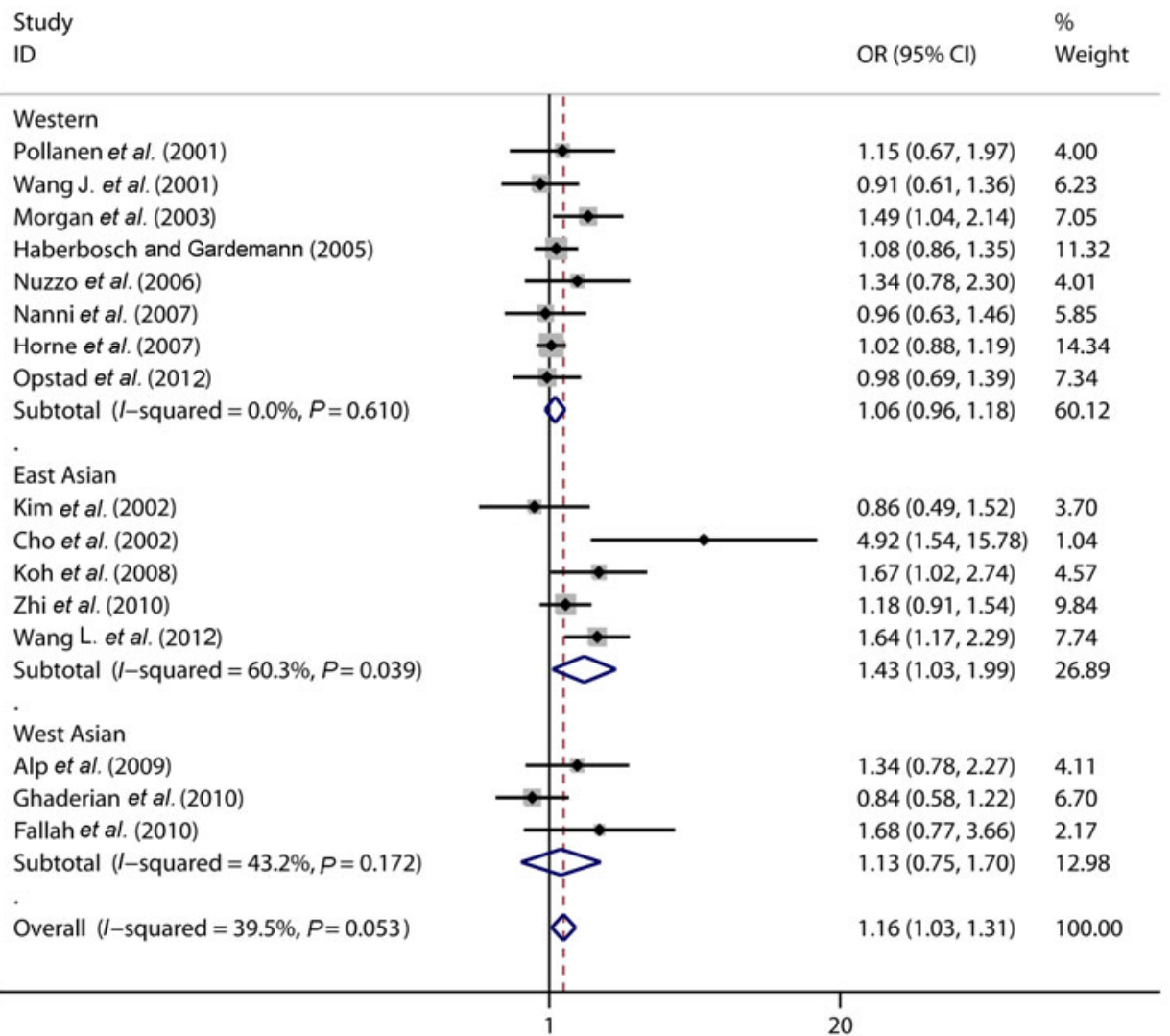

Fig. 2 Forest plot of association between C1562T and CAD

Study

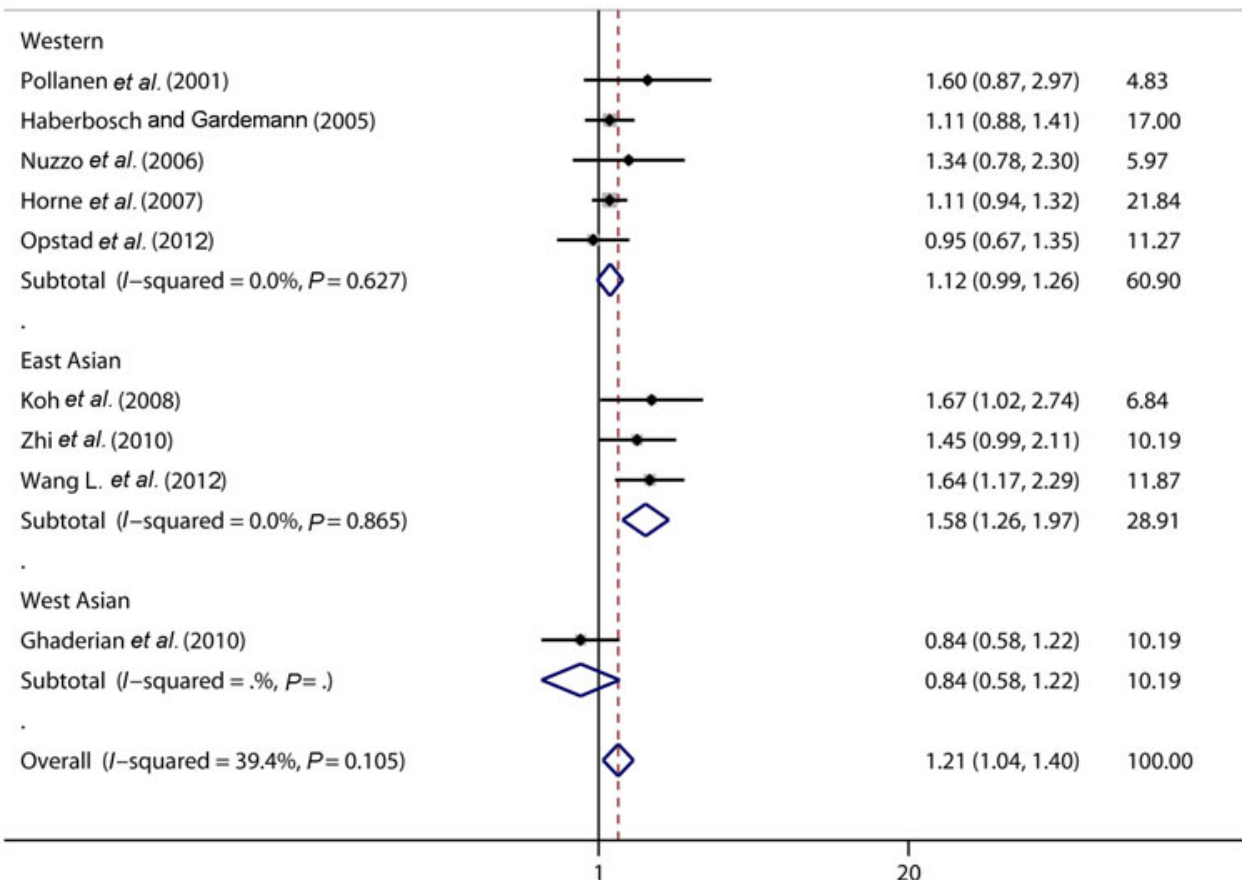

Fig. 3 Forest plot of association between C1562T and MI 
TT+TC genotype versus CC genotype for MI were: $\mathrm{OR}=1.21,95 \%$ CI $1.04-1.40, \quad P=0.012$ overall; $\mathrm{OR}=1.12,95 \%$ CI $0.99-1.26, P=0.078$ for Western populations; and $\mathrm{OR}=1.58,95 \%$ CI 1.26-1.97, $P=0.000$ for East Asians.

Evident heterogeneity could be observed in the East Asian subgroup from Fig. 2. However, when Cho et al. (2002)'s study was excluded, we found the heterogeneity decreased markedly ( $I^{2}$ from $60.3 \%$ to $43.3 \%, P$ value from 0.039 to 0.151 for East Asians; $I^{2}$ from $39.5 \%$ to $24.5 \%, P$ value from 0.053 to 0.183 overall) and the conclusions were still stable: $\mathrm{OR}=1.13,95 \%$ CI $1.02-1.26, P=0.021$ overall and $\mathrm{OR}=1.32,95 \%$ CI $1.02-1.72, P=0.034$ for East Asians. This indicated that this article may be the main source of heterogeneity as the sample in this article is relatively small compared to other studies.

Begg's funnel plot and Egger's test were chosen to detect whether there is potential publication bias in the studies. As is shown in Fig. 4, no significant publication bias was observed in $\mathrm{TT}+\mathrm{TC}$ versus $\mathrm{CC}$ genotype for CAD or MI (Egger's test $P=0.072$ and 0.263 , respectively).
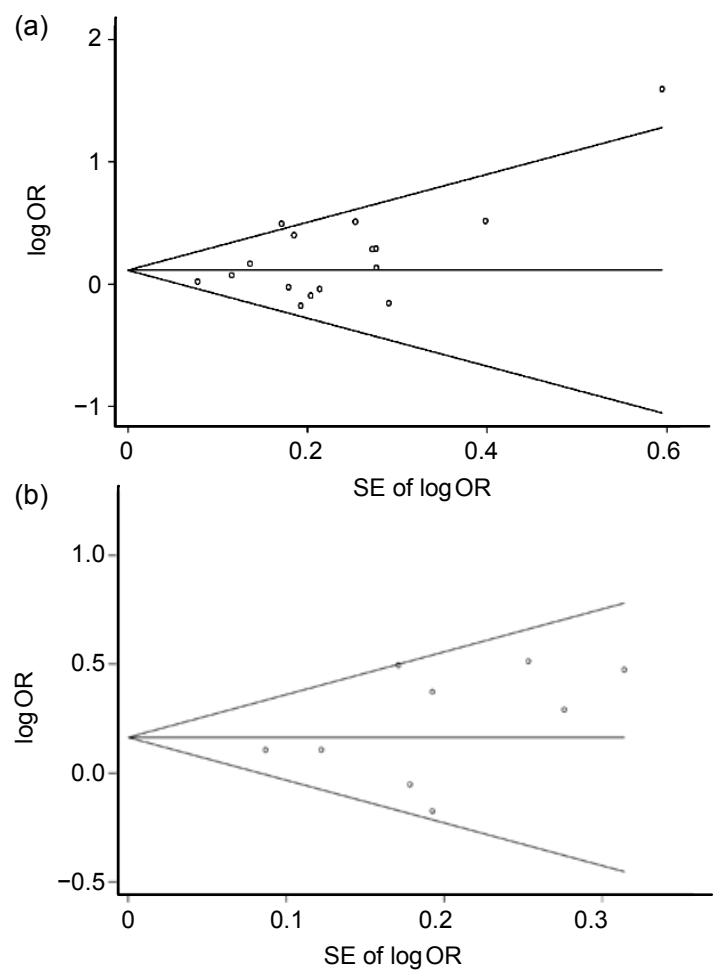

Fig. 4 Begg's funnel plot analysis of publication bias for CAD (a) and MI (b)

(a) Egger's test $P=0.072$; (b) Egger's test $P=0.263$. OR: odd ratio; SE: standard error

\section{Discussion}

As a member of MMP family, MMP-9 might be especially important in matrix degradation and the subsequent atheroslerotic plaque rupture because of its extensive substrate specificity and distal position in the proteolytic cascade reaction. Indeed, MMP-9 was highly expressed in the shoulder regions of advanced atherosclerotic lesions (Galis et al., 1994; Brown et al., 1995). Its concentration and activity were significantly higher in unstable atheroseclerotic plaque with intense inflammatory cell infiltration, hence contributing to the plaque rupture ultimately (Loftus et al., 2000; Pasterkamp et al., 2000). Some cross-sectional studies have reported that the plasma MMP-9 level was significantly higher in CAD patients, in particular in acute MI, than in control subjects (Kai et al., 1998; Tayebjee et al., 2005). Blankenberg et al. (2003) also showed that plasma MMP-9 concentration was higher in patients with $\mathrm{CAD}$ and might be a novel predictor of cardiovascular disease. However, some other cohort studies suggested that serum MMP-9 is not a strong predictor of CAD (Welsh et al., 2008; Jefferis et al., 2010). Some possible explanations are as follows: plasma MMP-9 level is affected by many factors, such as genetic polymorphisms of MMP-9, drugs, and other factors. Lacchini et al. (2010) found that there are interethnic differences in MMP-9 genetic polymorphisms. In our present study, we also confirmed that there was a significant ethnic difference of $\mathrm{T}$ allele distribution: the $\mathrm{T}$ allele distribution is much higher in CAD patients in East Asians but not in Westerners or West Asians. The relationship between MMP-9 genotype and MMP-9 levels is also quite distinct in different races. For example, no close association between MMP-9 genetic polymorphisms and plasma MMP-9 levels was found in healthy white subjects (Demacq et al., 2006; 2008; Lacchini et al., 2010). However, a positive association was confirmed in black subjects (Metzger et al., 2012). In addition, patients with CAD may take many drugs (such as statins) that could change plasma MMP-9 levels as indicated by some published studies (Souza-Costa et al., 2007; IzidoroToledo et al., 2011).

In our present meta-analysis, we found a significant association between MMP-9 C1562T polymorphisms and CAD and $\mathrm{MI}$ in overall population 
and East Asians. There are several possible mechanisms to explain the association between MMP-9 C1562T polymorphisms and CAD or MI. Firstly, in vitro transfection experiments and DNA-protein interaction assays (Zhang et al., 1999a) have suggested that $\mathrm{T}$ allele had a higher promoter activity than $\mathrm{C}$ allele: mutational $\mathrm{T}$ allele appeared to show preferential binding of a putative transcription repressor protein, and then the transcription repression process was relieved, contributing to production of more MMP-9. Secondly, MMP-9 might contribute to smooth muscle cell migration to intima, for smooth muscle cell migration rate to the vascular intima was markedly reduced in mice of MMP-9-knockout (Johnson and Galis, 2004). In addition, the expression and activity of MMP-9 are significantly higher in unstable atherosclerotic plaque with intense macrophage infiltration, and this may cause plaque instability and final rupture (Kai et al., 1998; Tayebjee et al., 2005). These above mechanisms would partially explain the relatively close relationship between $\mathrm{T}$ allele carriers (TT+TC genotypes) and CAD or MI.

There were some limitations to this meta-analysis. Firstly, no gene-gene or gene-environment interaction was evaluated. In fact, many other genes have been confirmed to be related to $\mathrm{CAD}$, such as myeloperoxidase (MPO) (Asselbergs et al., 2004) and adiponectin (Horne et al., 2007). Environmental factors, such as diet and pressure of living, could also facilitate the occurrence of CAD. Secondly, a relevant article (Zhang et al., 1999a) was excluded because we could not obtain sufficient information to calculate the genotype distribution. Finally, studies in other languages (not English) were not retrieved. That may lead to bias although the Begg's funnel plot and Egger's test showed no potential publication bias.

In conclusion, our meta-analysis suggested an obvious ethnic difference in the association between MMP-9 C1562T polymorphism and CAD. MMP-9 C1562T polymorphism was significantly associated with $\mathrm{CAD}$ or MI in East Asians. However, no significant association was observed in either West Asians or Western populations.

\section{Compliance with ethics guidelines}

Xiao WANG and Lei-zhi SHI declare that they have no conflict of interest.

This article does not contain any studies with human or animal subjects performed by any of the authors.

\section{References}

Alp, E., Menevse, S., Tulmac, M., et al., 2009. Lack of association between matrix metalloproteinase- 9 and endothelial nitric oxide synthase gene polymorphisms and coronary artery disease in Turkish population. DNA Cell Biol., 28(7):343-350. [doi:10.1089/dna.2009.0866]

Asselbergs, F.W., Reynolds, W.F., Cohen-Tervaert, J.W., et al., 2004. Myeloperoxidase polymorphism related to cardiovascular events in coronary artery disease. Am. J. Med., 116(6):429-430. [doi:10.1016/j.amjmed.2003.10.025]

Blankenberg, S., Rupprecht, H.J., Poirier, O., et al., 2003. Plasma concentrations and genetic variation of matrix metalloproteinase 9 and prognosis of patients with cardiovascular disease. Circulation, 107(12):1579-1585. [doi:10. 1161/01.CIR.0000058700.41738.12]

Brown, D.L., Hibbs, M.S., Kearney, M., et al., 1995. Identification of $92-\mathrm{kD}$ gelatinase in human coronary atherosclerotic lesions. Association of active enzyme synthesis with unstable angina. Circulation, 91(8):2125-2131. [doi:10. 1161/01.CIR.91.8.2125]

Cho, H.J., Chae, I.H., Park, K.W., et al., 2002. Functional polymorphism in the promoter region of the gelatinase $\mathrm{B}$ gene in relation to coronary artery disease and restenosis after percutaneous coronary intervention. J. Hum. Genet., 47(2):88-91. [doi:10.1007/s100380200006]

Demacq, C., de Souza, A.P., Machado, A.A., et al., 2006. Genetic polymorphism of matrix metalloproteinase (MMP)-9 does not affect plasma MMP-9 activity in healthy subjects. Clin. Chim. Acta, 365(1-2):183-187. [doi:10.1016/j.cca.2005.08.017]

Demacq, C., Vasconcellos, V.B., Marcaccini, A.M., et al., 2008. Functional polymorphisms in the promoter of the matrix metalloproteinase-9 (MMP-9) gene are not linked with significant plasma MMP-9 variations in healthy subjects. Clin. Chem. Lab. Med., 46(1):57-63. [doi:10. 1515/CCLM.2008.014]

Fallah, S., Seifi, M., Ghasemi, A., et al., 2010. Matrix metalloproteinase-9 and paraoxonase 1 Q/R192 gene polymorphisms and the risk of coronary artery stenosis in Iranian subjects. J. Clin. Lab. Anal., 24(5):305-310. [doi:10.1002/jcla.20406]

Galis, Z.S., Sukhova, G.K., Lark, M.W., et al., 1994. Increased expression of matrix metalloproteinases and matrix degrading activity in vulnerable regions of human atherosclerotic plaques. J. Clin. Invest., 94(6):2493-2503. [doi: 10.1172/JCI117619]

Ghaderian, S.M., Akbarzadeh Najar, R., Tabatabaei Panah, A.S., 2010. Genetic polymorphisms and plasma levels of matrix metalloproteinases and their relationships with developing acute myocardial infarction. Coron. Artery Dis., 21(6):330-335. [doi:10.1097/MCA.0b013e32833 ce065]

Haberbosch, W., Gardemann, A., 2005. Gelatinase B $\mathrm{C}_{(-1562)} \mathrm{T}$ polymorphism in relation to ischaemic heart disease. Scand. J. Clin. Lab. Invest., 65(6):513-522. [doi:10.1080/ 00365510500206575] 
Horne, B.D., Camp, N.J., Carlquist, J.F., et al., 2007. Multiplepolymorphism associations of 7 matrix metalloproteinase and tissue inhibitor metalloproteinase genes with myocardial infarction and angiographic coronary artery disease. Am. Heart J., 154(4):751-758. [doi:10.1016/j.ahj. 2007.06.030]

Izidoro-Toledo, T.C., Guimaraes, D.A., Belo, V.A., et al., 2011. Effects of statins on matrix metalloproteinases and their endogenous inhibitors in human endothelial cells. Naunyn-Schmiedeberg's Arch. Pharmacol., 383(6):547-554. [doi:10.1007/s00210-011-0623-0]

Jefferis, B.J., Whincup, P., Welsh, P., et al., 2010. Prospective study of matrix metalloproteinase- 9 and risk of myocardial infarction and stroke in older men and women. Atherosclerosis, 208(2):557-563. [doi:10.1016/j.atherosclerosis. 2009.08.018]

Johnson, C., Galis, Z.S., 2004. Matrix metalloproteinase-2 and -9 differentially regulate smooth muscle cell migration and cell-mediated collagen organization. Arterioscler. Thromb. Vasc. Biol., 24(1):54-60. [doi:10.1161/01.ATV. 0000100402.69997.C3]

Kai, H., Ikeda, H., Yasukawa, H., et al., 1998. Peripheral blood levels of matrix metalloproteases-2 and -9 are elevated in patients with acute coronary syndromes. J. Am. Coll. Cardiol., 32(2):368-372. [doi:10.1016/S0735-1097(98) 00250-2]

Kim, J.S., Park, H.Y., Kwon, J.H., et al., 2002. The roles of stromelysin-1 and the gelatinase B gene polymorphism in stable angina. Yonsei Med. J., 43(4):473-481.

Koh, Y.S., Chang, K., Kim, P.J., et al., 2008. A close relationship between functional polymorphism in the promoter region of matrix metalloproteinase- 9 and acute myocardial infarction. Int. J. Cardiol., 127(3):430-432. [doi:10.1016/j.ijcard.2007.04.107]

Lacchini, R., Metzger, I.F., Luizon, M., et al., 2010. Interethnic differences in the distribution of matrix metalloproteinases genetic polymorphisms are consistent with interethnic differences in disease prevalence. DNA Cell Biol., 29(11):649-655. [doi:10.1089/dna.2010.1056]

Loftus, I.M., Naylor, A.R., Goodall, S., et al., 2000. Increased matrix metalloproteinase- 9 activity in unstable carotid plaques. A potential role in acute plaque disruption. Stroke, 31(1):40-47. [doi:10.1161/01.STR.31.1.40]

Lopez, A.D., Mathers, C.D., Ezzati, M., et al., 2006. Global and regional burden of disease and risk factors, 2001: systematic analysis of population health data. Lancet, 367(9524):1747-1757. [doi:10.1016/S0140-6736(06)68 770-9]

Marenberg, M.E., Risch, N., Berkman, L.F., et al., 1994. Genetic susceptibility to death from coronary heart disease in a study of twins. N. Engl. J. Med., 330(15): 1041-1046. [doi:10.1056/NEJM199404143301503]

Metzger, I.F., Luizon, M.R., Lacchini, R., et al., 2012. Genetic variants in matrix metalloproteinase- 9 gene modify metalloproteinase-9 levels in black subjects. DNA Cell Biol., 31(4):504-510. [doi:10.1089/dna.2011.1388]
Morgan, A.R., Zhang, B., Tapper, W., et al., 2003. Haplotypic analysis of the MMP-9 gene in relation to coronary artery disease. J. Mol. Med. (Berl.), 81(5):321-326.

Nanni, S., Melandri, G., Hanemaaijer, R., et al., 2007. Matrix metalloproteinases in premature coronary atherosclerosis: influence of inhibitors, inflammation, and genetic polymorphisms. Transl. Res., 149(3):137-144. [doi:10.1016/ j.trsl.2006.09.001]

Newby, A.C., 2005. Dual role of matrix metalloproteinases (matrixins) in intimal thickening and atherosclerotic plaque rupture. Physiol. Rev., 85(1):1-31. [doi:10.1152/ physrev.00048.2003]

Nuzzo, D., Vasto, S., Balistreri, C.R., et al., 2006. Role of proinflammatory alleles in longevity and atherosclerosis: results of studies performed on $-1562 \mathrm{C} / \mathrm{T}$ MMP-9 in centenarians and myocardial infarction patients from sicily. Ann. N. Y. Acad. Sci., 1089(1):496-501. [doi:10. 1196/annals.1386.048]

Opstad, T.B., Pettersen, A.A., Weiss, T.W., et al., 2012. Genetic variation, gene-expression and circulating levels of matrix metalloproteinase- 9 in patients with stable coronary artery disease. Clin. Chim. Acta, 413(1-2): 113-120. [doi:10.1016/j.cca.2011.09.004]

Pasterkamp, G., Schoneveld, A.H., Hijnen, D.J., et al., 2000. Atherosclerotic arterial remodeling and the localization of macrophages and matrix metalloproteases 1, 2 and 9 in the human coronary artery. Atherosclerosis, 150(2): 245-253. [doi:10.1016/S0021-9150(99)00371-8]

Pollanen, P.J., Karhunen, P.J., Mikkelsson, J., et al., 2001. Coronary artery complicated lesion area is related to functional polymorphism of matrix metalloproteinase 9 gene: an autopsy study. Arterioscler. Thromb. Vasc. Biol., 21(9):1446-1450. [doi:10.1161/hq0901.095545]

Souza-Costa, D.C., Sandrim, V.C., Lopes, L.F., et al., 2007. Anti-inflammatory effects of atorvastatin: modulation by the $\mathrm{T}-786 \mathrm{C}$ polymorphism in the endothelial nitric oxide synthase gene. Atherosclerosis, 193(2):438-444. [doi:10. 1016/j.atherosclerosis.2006.07.020]

Tayebjee, M.H., Lip, G.Y., Tan, K.T., et al., 2005. Plasma matrix metalloproteinase-9, tissue inhibitor of metalloproteinase-2, and CD40 ligand levels in patients with stable coronary artery disease. Am. J. Cardiol., 96(3): 339-345. [doi:10.1016/j.amjcard.2005.03.072]

Wang, J., Warzecha, D., Wilcken, D., et al., 2001. Polymorphism in the gelatinase B gene and the severity of coronary arterial stenosis. Clin. Sci. (Lond.), 101(1):87-92. [doi:10.1042/CS20000317]

Wang, L., Ma, Y.T., Xie, X., et al., 2012. Interaction between MMP-9 gene polymorphisms and smoking in relation to myocardial infarction in a Uighur population. Clin. Appl. Thromb. Hemost., 18(1):72-78. [doi:10.1177/10760296 11412365]

Welsh, P., Whincup, P.H., Papacosta, O., et al., 2008. Serum matrix metalloproteinase- 9 and coronary heart disease: a prospective study in middle-aged men. QJM, 101(10): 785-791. [doi:10.1093/qjmed/hen088] 
Zhang, B., Ye, S., Herrmann, S.M., et al., 1999a. Functional polymorphism in the regulatory region of gelatinase $\mathrm{B}$ gene in relation to severity of coronary atherosclerosis. Circulation, 99(14):1788-1794. [doi:10.1161/01.CIR.99. 14.1788]

Zhang, B., Henney, A., Eriksson, P., et al., 1999b. Genetic variation at the matrix metalloproteinase-9 locus on chromosome 20q12.2-13.1. Hum. Genet., 105(5):418-423. [doi: $10.1007 / \mathrm{s} 004390051124]$

Zhi, H., Wang, H., Ren, L., et al., 2010. Functional polymorphisms of matrix metallopeptidase- 9 and risk of coronary artery disease in a Chinese population. Mol. Biol. Rep., 37(1):13-20. [doi:10.1007/s11033-009-9482-x]

\section{中文概要:}

本文题目: 基质金属蛋白酶-9 C1562T 基因多态性与冠心病关系的 meta 分析

Association of matrix metalloproteinase-9 $\mathrm{C1562 \textrm {T }}$ polymorphism and coronary artery disease: a meta-analysis

研究目的：探讨基质金属蛋白酶-9（MMP-9）C1562T 基因多态性与冠心病之间的关系。

创新要点: 通过综合分析, 明确了 MMP-9 C1562T 基因多态性与冠心病的发生存在种族差异性, 解决了 以往单个研究由于样本量偏少而得出不同结论的弊端。

研究方法: 利用 meta 分析可以扩大样本量的优势, 分析了 MMP-9 C1562T 基因多态性与冠心病间的关 系, 且研究结论更为可靠。

重要结论: MMP-9 C1562T 基因多态性与冠心病的发生存在显著的种族差异性: 在东亚人群中, MMP-9 C1562T 基因多态性与冠心病的发生密切相关; 在西方人群及西亚人群中, MMP-9 C1562T 基因多态性与冠心病的发生无显著相关性。

关键词组：冠心病；基质金属蛋白酶-9; 基因多态性; Meta 分析 